\title{
MARCAS DE ORALIDADE NO CADERNO KZUKA - UM OLHAR SOB A PERSPECTIVA DOS ESTUDOS CULTURAIS
}

\author{
Angela Dillmann Nunes Bicca ${ }^{1}$ \\ Ana Paula de Araujo Cunha ${ }^{2}$ \\ Raquel Neutzling Bierhals ${ }^{3}$
}

\begin{abstract}
Resumo
Neste estudo, buscamos compreender como as marcas de oralidade presentes no jornalismo estão implicadas na constituição de identidades culturais juvenis. Sob a perspectiva dos Estudos Culturais, discutimos, a partir da abordagem discursiva da Representação Cultural, os modos como o Caderno Kzuka - periódico semanal do jornal gaúcho Zero Hora - promove uma forma de Pedagogia Cultural, ao incorporar expressões e elementos tipicamente juvenis ao texto escrito no semanário.
\end{abstract}

Palavras-chave: Jornalismo; Oralidade; Pedagogias Culturais; Identidades

\section{INTRODUÇÃO}

Um caderno do jornal gaúcho Zero Hora, denominado Kzuka, tem sido endereçado para guris e gurias, ao apresentar em suas páginas matérias sobre artistas de sua preferência, roupas e acessórios da moda, novidades tecnológicas, eventos culturais, entre outros temas. Uma das peculiaridades dessas reportagens é a redação fortemente permeada pelos modos como esses/as jovens falam - sua linguagem, portanto, foco deste estudo. Ora, a linguagem

\footnotetext{
${ }^{1}$ Doutora em Educação, pela UFRGS. Endereço: Rua Pinto Martins 271, apto 204. Pelotas, Rio Grande do Sul, Brasil. Endereço eletrônico: angela.bicca@ hotmail.com

${ }^{2}$ Doutora em Letras, pela UFRGS. Endereço: Praça Vinte de Setembro, 455 - Sala 321b. Pelotas-RS, Brasil. Endereço eletrônico: cpead.anapcunha@ gmail.com

${ }^{3}$ Especialista em Linguagens e pesquisadora do GP-Linguagens Verbo/Visuais e Tecnologias. Jornalista da UCPEL e UFPEL. Endereço: Rua Gomes Carneio, 1, sala 444, bloco B. Pelotas-RS, Brasil. Endereço eletrônico: quelbier@gmail.com
} 
per se, assim como os códigos visuais ou gráficos, constitui elemento central da prática comunicativa em várias dimensões, a considerar o fato de nosso ler, ouvir, falar e escrever estar impregnado de palavras, imagens e sons a partir dos quais produzimos sentidos. Nesta perspectiva, especialmente no âmbito jornalístico, importa considerar, entre outros aspectos: (i) estrutura, semântica e significado social do texto a ser veiculado; (ii) atitudes e decisões sobre o uso da linguagem; (iii) visão de mundo; (iv) perfis da comunidade ou público alvo; e (v) modo de veiculação da matéria (dêitico, visual, ideológico). Cunha e Bierhals (2014) investigaram marcas de oralidade que permeiam o jornalismo impresso voltado para o público jovem. As autoras analisaram excertos de publicações do caderno Kzuka na Zero, identificando similitudes e diferenças entre o texto jornalístico clássico e o produzido no referido suplemento do jornal Zero Hora. As lentes analíticas foram eminentemente linguísticas, tendo como foco os níveis discursivo e lexical. Em síntese a investigação apontou que a linguagem veiculada no Caderno apresenta características do texto de revista semanal. As marcas de oralidade serviriam, nesse caso, para "estabelecer uma espécie de cumplicidade com o público alvo" (CUNHA e BIERHALS, 2014, p.180).

Para além do estudo de Cunha e Bierhals (2014), ampliamos o escopo deste estudo à análise dos modos como as marcas de oralidade presentes no jornalismo, particularmente no caderno Kzuka, estão possivelmente implicadas na constituição de identidades culturais juvenis. Partimos, pois, da ideia de que a mídia é também uma forma de pedagogia cultural, ensinando valores dominantes, modos de pensar e se comportar, estilos e modas, provendo, por conseguinte, recursos para a constituição de identidades (KELLNER, 1995).

Para realizar este estudo, inserimo-nos nos Estudos Culturais de inspiração pósestruturalista, perspectiva teórica que nos permitiu compreender como operam as marcas de oralidade mais frequentemente encontradas no periódico em questão, o qual foi escolhido para essa análise, tendo em vista o seu direcionamento para o público jovem.

\section{UM JORNAL FEITO PRA GALERA}

O jornal $\mathrm{Kzuka}^{4}$ foi criado juntamente com a empresa de Consultoria, Marketing e Relacionamento Kzuka, como registram Marques (2007), Orengo (2009) e Bertinetti (2012),

\footnotetext{
${ }^{4}$ É interessante comentar que o uso da letra $\mathrm{K}$, em termos cunhados por grupos culturais juvenis, vem sofrendo mutações semânticas. Como registrou Canevacci (2005), na década de 1970 a letra K era um indicador de grupos
} 
BICCA, A. D. N.; CUNHA, A. P. A.; BIERHALS, R. N.

ao discutirem os modos como essa empresa estabelece formas de comunicação com o público jovem. Posteriormente, a empresa Kzuka se tornou parceira do Grupo RBS, época em que o jornal Kzuka passou a ser publicado como um caderno integrante do jornal Zero Hora. A empresa mantém, além do jornal, um portal na Internet, programas na Rádio Atlântida e no canal TVCOM, bem como perfil em redes sociais.

Inicialmente, o jornal não era vendido, mas distribuído gratuitamente em escolas particulares e no Colégio Militar da cidade de Porto Alegre, como registrou Marques (2007). De acordo com esta autora, o "pessoal” do Kzuka mantém visitas periódicas a essas escolas, que ocorrem durante os intervalos das aulas, buscando manter um vínculo estreito com esses jovens gaúchos.

Por meio de tais ações, a empresa Kzuka busca direcionar seus produtos para jovens com os quais estaria conversando de "igual para igual". Para fazer isso, a empresa mantém uma equipe de profissionais denominada Comunik, que se dedica a atualizar os modos de interagir com o público jovem, buscando

trabalhar temas polêmicos e atuais de uma forma clara, objetiva e inserida no contexto dos adolescentes. A linguagem jovem e alinhada com o público, permite estimular a reflexão e a discussão sadia em sala de aula (KZUKA, 2010).

Um dos produtos de mídia mais destacados da empresa Kzuka é o Caderno Jovem, encartado todas as sextas-feiras nos seis principais jornais do Grupo RBS que circulam no Rio Grande do Sul e em Santa Catariana, a saber: Zero Hora, O Pioneiro, Diário de Santa Maria, Diário Catarinense, A Notícia e Jornal de Santa Catarina. Esse caderno, que é objeto da análise que realizamos, possui de oito a doze páginas nas quais aborda temas tais como viagens, música, esporte, cultura pop e moda, valendo-se de uma linguagem cheia de expressões linguísticas que são recorrentemente associadas à juventude. A questão que nos instigou aborda, neste texto, os modos como o uso de uma linguagem coloquial alimentada pela oralidade vincularia um veículo de comunicação aos jovens, participando da construção de suas identidades.

culturais juvenis que faziam oposição a diferentes formas de autoritarismo. Palavras eram escritas com a letra K para que fossem associadas ao autoritarismo. No entanto, esse sentido mudou de forma importante durante as décadas de 1980 e 1990. A letra K passou a compor palavras importantes para jovens que mostram estranhamento às normas estabelecidas. 
Nessa perspectiva, é importante referir que o Kzuka é direcionado para jovens de 13 a 25 anos das classes A e B (BERTINETTI, 2012), o que parece justificar que apareçam, com muita frequência, nas páginas do referido caderno, jovens estudantes de escolas particulares e de universidades do sul do Brasil aproveitando um período de suas vidas no qual, além de estudar, podem fazer viagens de lazer, assistir a diversos programas de TV e rádio, inteirar-se das músicas de sucesso, saber detalhes sobre a vida das celebridades que admiram, enfim, podem consumir as mais diversas opções de lazer sem descuidar um só instante da aparência, consumindo, também, os mais variados objetos. Também é possível encontrar no Kzuka anúncios de cursinhos Pré-vestibulares, de cursos de línguas, de lojas de roupas, bem como de eventos culturais diversos.

\section{ENSINANDO COMO PERTENCER À GALERA}

Como indicou Marques (2007), o Kzuka é um objeto que "fala", um artefato cultural que constitui identidades culturais juvenis através da linguagem que recruta para sua composição. Em outras palavras, o Kzuka aponta o que é certo ou errado, válido ou inválido, normal ou anormal, desejado ou indesejado, para que alguém pertença à sua "galera". Enfim, o Kzuka possui uma dimensão pedagógica que ensina a ser jovem e a pertencer a um determinado grupo cultural, recorrendo, particularmente, a formas de expressão peculiares com fortes marcas de oralidade.

Podemos dizer que o jornal Kzuka funciona como um espaço de produção de saber (GARBIN, 2003) ou como um campo de visibilidade de discursos e enunciados (PROVIN e FABRIS, 2011), o que está relacionado com a ampliação do campo da Educação que tem assumido como educativos filmes, peças publicitárias, textos jornalísticos, fotografias, reportagens em revistas, desenhos animados, programas de TV, sites da Internet (GIROUX, 1995; STEINBERG, 1997; KELLNER, 2001), entre outros.

Esses trabalhos conferem atenção aos modos como as produções e artefatos culturais, os quais vêm se multiplicando e ganhando importância no mundo em que vivemos, têm contribuído, em especial, para a constituição de nossas identidades culturais. Aliás, um destaque que tem ajudado a deslocar a escola e a academia da posição privilegiada que adquiriu na era moderna de elaboração, disseminação e legitimação de saberes. 
BICCA, A. D. N.; CUNHA, A. P. A.; BIERHALS, R. N.

Por isso, consideramos tão pertinente abordar, em um trabalho inserido no campo da Educação, os efeitos que um veículo de comunicação produz na constituição dos jovens contemporâneos e no mundo em que habitam. Ou seja, o que estamos fazendo é levar em consideração que a cultura atua nos mais diversos espaços da vida cotidiana, mobilizando os mais diversos sujeitos a atuarem na produção ativa de suas identidades culturais. Ao fazer isso, instâncias que não eram usualmente consideradas educativas em função de atentarem fortemente para outros interesses, particularmente os voltados ao entretenimento e ao consumo, como indicou Steinberg (1997), estariam também ensinando muitas coisas para muitos sujeitos, praticando uma forma de pedagogia sedutora e prazerosa.

Estamos, portanto, tomando cadernos de jornal como espaços educativos, explorando seu caráter pedagógico para compreender como participam da produção de identidades juvenis que se assemelham a tribos urbanas (MAFFESOLI, 2010). Com o termo tribo o autor buscou indicar o surgimento, nas sociedades contemporâneas, de agrupamentos espontâneos e sazonais, baseados no prazer de estar junto e nos laços afetivos. Tal constituição de grupos culturais tem ajudado a mostrar a necessidade de muitos jovens buscarem pertencer a alguma coisa, a alguma crença, a alguma tribo, como destacaram Garbin (2003) e Schmidt (2006) ao discutirem a produção de identidades juvenis a partir de diferentes artefatos culturais.

Entendemos, portanto, que os cadernos inseridos em jornais têm possibilitado a constituição de estilos de vida jovem que se produzem associados, preferencialmente (e não exclusivamente), ao lazer, ao ócio, ao consumo, ao tempo livre ou aos espaços entre as atividades relacionadas ao trabalho, situação que não está necessariamente ligada a uma faixa etária particular. Assim, embora o caderno de jornal analisado seja produzido visando a uma faixa etária que vai dos 13 aos 25 anos, não assumimos que a juventude, entendida como uma categoria analítica, seja definida por alguma faixa etária ou geração particular. Como mostrou Velho (2006), a juventude pode ser entendida como um estilo de vida cuja definição é sempre instável, nebulosa e sujeita a constantes revisões. A juventude, assim como a infância, a adolescência, a vida adulta e a velhice, não é categoria que se possa estabelecer a partir de critérios fixos e indiscutíveis, o que inclui a idade que as pessoas têm. Assim, é possível compreender a juventude como um estilo de vida que pode ser estendido para pessoas de todas as idades e não mais como a fase que precederia a vida adulta (GARBIN, 2003; CANEVACCI, 2005; SCHMIDT, 2006; VELHO, 2006; MACHADO, 2011). Aliás, parecenos que o Caderno Kzuka pode atingir bem mais leitores/as do que os que constituem seu 
público preferencial, contribuindo, portanto, para produzir formas de ser jovem reconhecidas e desejadas por pessoas que não estão compreendidas em uma faixa etária.

Os estilos de vida juvenis são também fortemente voltados para o consumo. Dessa forma, o mercado estaria capturando indivíduos de todas as idades para formas de consumir associadas aos diferentes modos de ser jovem, o que tem levado o consumo a se constituir como um aspecto fundamental da construção identitária de grupos culturais juvenis, como destacou Matos (2011). Porém, o consumo não é apenas observado quando se realiza a compra objetos e serviços. Além da aquisição de objetos e da contratação de serviços, como indicou a autora (idem), pode-se considerar como uma forma de consumo a apropriação de textos midiáticos diversos.

A apropriação de um texto midiático inclui a compreensão e o uso de formas de expressão que são recorrentes na produção desse mesmo texto. Dessa forma, compreendemos que o modo como o Caderno Kzuka recorre a aspectos da oralidade para constituir os seus textos contribui para endereçar o referido caderno a um público em particular, que tem se valido dessas formas de expressão para constituir suas identidades culturais.

Como mostraram Bauman (2005), Woodward (2005) e Hall (2005), a identidade cultural está se tornando cada vez mais uma tarefa ser assumida e realizada, sem que exista um ponto final previsto para esse processo. Tal compreensão decorre da dificuldade cada vez maior de explicar a identidade como algo natural, cristalizado, essencial, estável, coerente, unificado, permanente, homogêneo ou como um conjunto fixo de características que permita dizer o que uma pessoa é. Ou seja, há algum tempo atrás a produção de identidades partia, com muita frequência, de sistemas de pertencimento tais como a família, a religião e a nação. Porém essas formas de pertencimento têm perdido força para esforços de inserção das pessoas em grupos muitas vezes temporários, cujos elos que ligam seus integrantes são bem mais fáceis de romper do que tendia a ocorrer nos sistemas de pertencimento mais antigos.

Sob o ponto de vista das teorizações pós-estruturalistas assumido neste estudo, a identidade e a diferença, como indicou Hall (2005), além de interdependentes, são discursivamente constituídas, ou, ainda, são produtos da linguagem. Ou seja, identidade e diferença não estão prontas na natureza nem possuem uma essência a ser identificada; identidade e diferença são ativamente produzidas através das diversas formas como são representadas. Neste sentido, dizer que alguém pertence a um determinado grupo social significa associar-lhe uma série de características relacionadas ao modo de vida assumido, 
BICCA, A. D. N.; CUNHA, A. P. A.; BIERHALS, R. N.

mesmo que temporariamente, ao mesmo tempo em que se diferencia esse modo de vida de vários outros existentes. Cabe destacar que isso decorre da instabilidade da linguagem que não mantém um determinado conjunto de elementos unidos definitivamente, como mostrou Silva (2005). As associações entre as pessoas e seus modos de vida, quando pensadas sob a ótica aqui assumida, ocorrem de uma forma específica e em um determinado tempo, pelos recursos linguísticos ali requeridos.

Nessa perspectiva, podemos indicar que o recurso à oralidade na escrita do Caderno Kzuka contribui para constituir modos de ser jovem neste espaço midiático. Aliás, um grupo que assume como seus alguns modos de expressão verbal que indicariam a possibilidade de o jornal "falar diretamente para a galera", ou seja, comunicar-se com um grupo cultural valendo-se de formas de expressão que são usadas pelo mesmo grupo em diversas situações de comunicação. Essa é uma das formas pelas quais o Caderno Kzuka representa esses modos de ser jovem. O conceito de representação cultural na sua abordagem construcionista (HALL, 1997) tem forte relação com a noção foucaultiana de discurso. Sob essa ótica, o termo representação não é tomando como sinônimo de imagens ou de palavras capazes de refletir algo que exista no mundo real. Possibilita, isto sim, levar em consideração a maneira por meio da qual os entes do mundo são constituídos, estruturando a forma como algo é pensado e os modos como agimos a partir de tais formas de pensar. Enfim, representação cultural diz respeito aos processos de produção e estabelecimento dos significados para os seres e coisas do mundo.

\section{LINGUAGEM JORNALÍSTICA E OS MODOS DE FALAR COM A GALERA DO KZUKA}

O primeiro semanário impresso de que se tem conhecimento apareceu em Londres, em 1622, como referiu Rodrigues (1999). Porém esse semanário, da forma como o conhecemos hoje, não é tão antigo. Sua forma atual foi desenvolvida entre os anos de 1930 e 1969, como indicou Lustosa (1996, p.67).

Algumas das características que hoje reconhecemos ser recorrentes nos textos jornalísticos que pretendem informar "a verdade dos fatos", tais como a de deixar opiniões e comentários em segundo plano, em nome de uma pretensa objetividade, e o tipo de diagramação, foram sendo elaboradas ao longo do tempo. Conforme Lustosa (1996.), podemse identificar cinco fases pelas quais o texto jornalístico teria passado. A primeira ocorreu de 
1808 a 1827, quando a escrita dos textos jornalísticos era repleta de opiniões, juízos de valor, observações pessoais, além de buscar zelar pelos princípios morais e cristãos. Na segunda fase, de 1827 a 1889, os textos buscavam narrar "fatos" seguindo a ordem cronológica dos acontecimentos, com acentuada redução da opinião dos jornalistas em relação ao período anterior. Esse é o mesmo período em que surgem as agências de notícias que trabalham associadas aos grandes veículos de comunicação. Entre os anos 1889 a 1930, período que o autor (idem) refere como a terceira fase, os veículos começam a adotar notícias quase que exclusivamente informativas, ou seja, "tendo como norma a exclusão de qualquer juízo de valor ou opinião pessoal do jornalista" (p.67). No quarto período, que vai de 1930 a 1969, os veículos - em especial os impressos - desenvolvem uma técnica especial de construção do texto informativo valendo-se do que foi denominado lide (o primeiro parágrafo da notícia contendo as perguntas básicas sobre determinado assunto). De 1969 até agora, período que constitui a quinta fase, prevaleceu "a cultura visual, imposta pela televisão, que define o padrão estético dos veículos impressos, especialmente jornais e revistas" (LUSTOSA, p.67). Esse período é também caracterizado como aquele em que o jornalismo tem buscado processar informação "em escala industrial e para consumo imediato" (LAGE, 1998, p.35). $\mathrm{Ou}$, ainda, a forma de produzir os jornais tem sido pautada pela busca de produzir textos informativos de leitura rápida e objetiva.

Assim, podemos dizer que o caderno Kzuka foi criado em tempos nos quais a cultura visual possui grande destaque, ao mesmo tempo em que há preocupação dos profissionais que escrevem os jornais em atingir os seus públicos de forma rápida, o que exige direcionar o texto do periódico àquele(s) grupo(s) (ou tribo(s), no caso do veículo em foco) que se pretende atingir. Ao comentar a mesma questão, Jacira Rodrigues (2003) teceu o seguinte comentário:

\footnotetext{
Enquanto o jornalismo se profissionalizou, alteraram-se as formas de redigir. A pomposidade da retórica sai das páginas do periódico, assim como os escritores se vão das salas de redação. Cada palavra passa a ser medida pela sua essencialidade, visando à compreensão do fato na hora da leitura (RODRIGUES, 2003, p. 15).
}

Nesta perspectiva, os textos jornalísticos teriam incorporado expressões oriundas da linguagem coloquial a fim de produzir metáforas que possibilitariam uma maior proximidade com os/as seus/suas leitores/as, como indicou Lage (1998). Os textos jornalísticos, mesmo mantendo uma forma de padronização, assumem, também, a tarefa de incorporar termos e 
BICCA, A. D. N.; CUNHA, A. P. A.; BIERHALS, R. N.

expressões que ganham as ruas ou são correntes no dia-a-dia da população. Para Bordenave (1986, p.20), o jornal cumpre o papel de provisão de informação e também promove contatos sociais.

Além disso, a periodicidade semanal do Caderno Kzuka possibilita que os comunicadores que o produzem aproximem o referido jornal dos modos como as revistas semanais são elaboradas. De acordo com Vilas Boas (1996), o tempo de que os periódicos semanais dispõem para produzir suas matérias permite que se elaborem materiais mais criativos, utilizando-se de recursos estilísticos que geralmente não combinam com a velocidade do jornalismo diário. Dessa forma, a periodicidade semanal "possibilita a elaboração/produção de um texto prazeroso de ler, rompendo as amarras da padronização cotidiana" (VILAS BOAS, 1996, p. 9).

O Jornal Kzuka, apresentando textos e composições de imagens elaborados no espaço temporal de que dispõem os periódicos semanais, busca seduzir e conquistar o/a leitor/a, valendo-se, muitas vezes de termos e expressões coloquiais, como já referimos anteriormente. No entanto, isso não significa que os padrões de redação e de diagramação de um jornal sejam negligenciados. Ao abordar o modo como os textos de uma revista são produzidos, Vilas Boas (1996) indicou que o texto escrito

para uma revista também segue os padrões jornalísticos, mas isto não impede que palavras, frases e períodos tenham um 'rebolado' diferente. [...] $\mathrm{Na}$ revista as palavras podem ser usadas não apenas com o sentido que lhes atribuem os dicionários. [...] No texto diário de jornal, o valor conotativo só é aceito em situações muito especiais (VILAS BOAS, 1996, p. 18).

É razoável afirmar, portanto, que há, na literatura especializada na redação de periódicos semanais, a compreensão de que estes seriam os veículos de comunicação em relação aos quais se possui mais liberdade para romper com os esforços de velocidade e padronização, recorrentes no jornalismo diário. A periodicidade semanal abriria, dessa forma, mais espaço para experimentações linguísticas e visuais, o que inclui a inserção de expressões coloquiais e de formas de expressão recorrentes na linguagem falada ao texto dos jornais.

De acordo com Dias (1996, p.15), em diversas situações de comunicação a linguagem coloquial tem sido requerida, instalando-se nas páginas dos dicionários e, também, nas páginas dos jornais que são "muito mais receptivos a essas transformações" (DIAS, 1996, p.16). Isso ocorre muito embora os Manuais de Redação utilizados nos veículos de comunicação primem pelo uso da gramática tradicional. É fato, pois, que os jornalistas têm 
admitido certa tolerância ao uso de termos coloquiais em algumas situações. Contrariamente às produções textuais mais "livres" (grifo nosso), o Manual de Redação da Folha de São Paulo, por exemplo, registra que o texto de jornal deve "ter estilo próximo ao da linguagem cotidiana, sem deixar de ser fiel à norma culta, evitando erros gramaticais, gíria, vulgaridade e deselegância" (MANUAL DA REDAÇÃO, 2002, p.77). Nessa perspectiva normativa, por conseguinte, a redação "descolada" do Caderno Kzuka seria colocada sob-rasura, caso fossem totalmente desconsideradas as características de seu público alvo.

Mas, quando afirmamos que as formas de expressão oriundas da linguagem verbal oral, das quais o Caderno Kzuka tem se valido, predominam em seu texto, não estamos dizendo que seus/suas redatores/as deixem de recorrer à linguagem formal em algumas situações. Ao abordar assuntos mais "sérios", por exemplo, o caderno é escrito com bem mais formalidade do que o habitual. Mesmo que a reportagem de onde foi retirado o trecho transcrito a seguir apresente gírias e momentos de descontração para abordar a prática das meninas de "ficar" não apenas com os meninos, mas também entre si, isso não se mantém por toda a reportagem.

Para a psiquiatra infantil e professora da PUCRS, Gibsi Rocha, se uma menina experimenta ficar com outra apenas para repetir um comportamento e ser aceita no seu grupo (atitude muito comum nessa fase), corre mais riscos de se confundir. - A menina pode sentir um prazer momentâneo e acabar pensando que é gay, o que pode não ser verdade - observa Gibsi. [...] Explicar um fenômeno que ainda é considerado novo para especialistas em adolescentes é um desafio que dá brecha para julgamentos preconceituosos. (KZUKA, Ed. 139, p.04).

Neste trecho, o jornal recorre a uma especialista para opinar a respeito do tema em discussão. Ripoll (2001), ao analisar as matérias veiculadas nas revistas Veja, Exame, Amanhã e Superinteressante, que abordaram genética e biotecnologia entre os anos 1998 e 2000, apontou que convidar um especialista para abordar o tema em discussão em uma matéria jornalística é uma estratégia que confere legitimidade e confiabilidade ao texto.

Portanto, no mesmo trecho é possível observar como o tema da reportagem é tratado com um tom mais "sério" do que é habitual em outros trechos da mesma reportagem e do mesmo jornal, escrito sem o uso de gírias e de formas coloquiais de comunicação. Neste caso, a fala da especialista é transcrita como uma citação, usando-se aspas, tal como seria feito em outros tipos de texto jornalístico. Como disse Lage (1998), esse tipo de citação acentua o "efeito de realidade" no jornalismo, recurso que também contribui para conferir veracidade e 
BICCA, A. D. N.; CUNHA, A. P. A.; BIERHALS, R. N.

confiabilidade ao que está sendo dito naquele momento na reportagem. Enfim, o espaço dedicado a tratar de um assunto "sério", mesmo em um jornal voltado para públicos jovens, não é espaço de grande informalidade na linguagem usada para a comunicação.

Porém, a gíria, como comentou Pretti (2006), é um signo identificador de um grupo social - pessoas que partilham padrões organizados de interação ou que compartilhem uma consciência de filiação e interação. Dessa forma, com o uso da gíria pode endereçar o texto de um jornal para o grupo que se vale dela na linguagem cotidiana e que atribui a ela um sentido particular.

Ao "chamar" jovens leitores/as a assumir posições-de-sujeito produzidas na interação deles/as com o jornal, que, de forma criativa, veicula as marcas de oralidade como uma de suas importantes características, o Kzuka estaria endereçando seu texto ao seu público. Esse endereçamento, por sua vez, tem relação com a constituição de identidades culturais juvenis, situação que pode ser pensada, também, a partir da noção de modos de endereçamento, oriunda dos estudos de cinema (ELLSWORT, 2001). Essa noção, quando usada para discutir a produção cinematográfica, possibilita compreender que os sentidos associados a um filme estão relacionados aos estímulos e recompensas oferecidos pelo filme aos seus públicos, como indicou Ellsworth (2001). Isso levaria os/as espectadores/as de um filme a assumirem determinadas posições relativas ao gênero, ao status social, à raça, à nacionalidade, por exemplo, refutando tantas outras posições existentes. A relação entre um filme e o que o/a espectador/a do filme experiência pode ser resumida na pergunta "quem este filme pensa que você é?", enunciada por Ellsworth (2001, p.11).

No entanto, a discussão acerca dos modos de endereçamento não tem ficado restrita ao campo do cinema, possibilitando refletir-se, por exemplo, a respeito da relação entre um romance e seu/sua leitor/a, entre uma pintura e quem a contempla, entre um determinado currículo escolar e os/as sujeitos escolares, bem como da relação entre um texto de jornal e seus/suas leitores/as. Neste sentido, podemos dizer que filmes, pinturas, livros, currículos escolares, fotografias, comerciais de TV, cartas, blogs, jornais, entre outros artefatos, são feitos para alguém; eles visam, imaginam e desejam envolver/atingir um determinado público.

Havemos de sublinhar, porém, que, de acordo com a discussão sobre modos de endereçamento de Ellsworth (2001), há um espaço entre o que um texto pensa que o/a leitor/a é e o que o/a próprio/a leitor/a pensa que é. Assim, mesmo que os/as jornalistas que produzem o Kzuka possam presumir qual é o público daquele texto e tomar decisões acerca dos temas a tratar, do que desperta atenção, do que causa repúdio e de que respostas podem ser esperadas 
em relação àquele texto, não há qualquer garantia de que o endereçamento produza os efeitos esperados. Pode haver, portanto, um "erro de alvo" inevitável, o que torna conceito de modos de endereçamento uma forma relevante de explicação a respeito do porquê de vários/as leitores/as assumirem posições diferentes em relação a um texto ou do porquê de um mesmo/a leitor/a mudar de posição eventualmente.

O uso da gíria, aqui considerado como um modo de endereçamento, tem sido um dos recursos de que o Caderno Kzuka tem lançado mão para estabelecer um diálogo com o/a leitor/a, evocando proximidade e informalidade, ou seja, por meio de tais expressões é possível redigir um texto que lembra, sobremaneira, uma conversa entre amigos/as, como podemos ver nos trechos abaixo:

Que tal curtir a domingueira ao som de bandas gaúchas? A partir das 15h, no Scooba, vai rolar festerê com as bandas Área Restrita e douyoulike? (KZUKA, 2010, ed. 145, p. 2).

Quer curtir esse super show de barbada? O Kzuka vai dar quatro pares de ingressos para curtir a festa no Camarote Kzuka! Então, corre pro kzuka.com.br e responda [...] (KZUKA,2010, ed. 145, p.4).

Apesar de ter virado motivo de brincadeira entre as amigas, se defende dizendo que as melhores festas rolam no findi. (KZUKA,2010, ed. 145, p. 5).

Na agenda, é possível ver que os caras [...] fazem show quase todos os dias. (KZUKA, 2010, ed. 146, p.4)

Nestes trechos, observamos a presença de algumas gírias, como, por exemplo: "curtir", "domingueira", "festerê", "barbada", "rolar", "findi” e "caras". A expressão "curtir" é usada para designar o ato de apreciar algo; "domingueira" indica festas que ocorrem nos dias de domingo e advém do vocabulário gauchesco; "festerê" é também usada para indicar momentos festivos; "barbada" é usada para designar o que é fácil de ser feito ou obtido; "rolar" indica que algo vai acontecer; "findi" designa final de semana; "caras", por sua vez, indica um grupo de pessoas. Observando as gírias referidas, podemos dizer que todas elas se vinculam a atividades de lazer, que, aliás, são as mais correntemente associadas aos estilos de vida dos jovens, como já apontamos, anteriormente.

A gíria, como apontou Pretti (2003), é um fenômeno predominantemente urbano, associada a grupos que pretendem criar formas peculiares de comunicação, reforçando laços de convívio social e diferenciando-se de outros grupos. Aliás, uma das marcas distintivas 
BICCA, A. D. N.; CUNHA, A. P. A.; BIERHALS, R. N.

mais recorrentes dos grupos culturais juvenis. Neste sentido, as gírias, assim como as formas de vestir, os cortes de cabelo, os objetos de consumo, por exemplo, configuram-se como elementos constitutivos da identidade cultural dos sujeitos.

Outro ponto a sublinhar, como destacou o autor, a gíria tende a não permanecer restrita ao grupo onde surgiu, passando a circular fora desse, incorporando-se ao modo como faltantes daquela mesma língua se expressam. Além disso, muitas vezes a gíria surge, espalha-se, desaparece e cai em desuso muito rapidamente. Esse caráter de efemeridade da gíria possibilita, portanto, indicar quem pertence a um determinado grupo cultural em um dado momento. Ou, ainda, o uso de gírias que caíram em desuso por um grupo indicaria afastamentos em relação a esse mesmo grupo cultural.

Muitas vezes a ampliação do âmbito de circulação de uma gíria se dá com o uso desta em veículos de comunicação. Um exemplo disso, apontado por Pretti (2003), é a circulação de gírias usadas no Brasil entre os portugueses em função da veiculação de novelas brasileiras no país lusitano. Nesta perspectiva, podemos dizer que o Caderno Kzuka estaria contribuindo para que gírias usadas em seu texto venham a ser conhecidas e incorporadas por um número cada vez maior de pessoas, de todas as idades e que residem em diversos locais onde o jornal circula.

Além disso, o Kzuka não apenas usa gírias quando se dirige aos seus públicos, mas as mantém quando se encontram na fala de algum/a entrevistado/a, como podemos ler no excerto abaixo:

- Não dá tempo de curtir a praia, mais trabalhar na noite é muito irado, compensa - conta o guri, que pensa em juntar uma grana e aproveitar a praia em fevereiro. (KZUKA, 2010, ed. 145, p.5).

Neste mesmo exemplo, podemos observar que o entrevistado é nomeado de "guri”, uma expressão bastante usada no Rio Grande do Sul para designar os meninos. Possivelmente, com tal estratégia, o jornal tenta marcar o pertencimento do entrevistado ao grupo cultural para o qual endereça seus textos.

Em alguns casos, as gírias são usadas como forma de emitir juízos de valor a respeito de alguma coisa ou alguém, como aparece nos excertos abaixo: 
As esportivas ${ }^{5}$ sempre mandam bem. (KZUKA, 2010b, ed. 146, p. 6).

Enquanto aguarda um convite para passar um tempo na praia, a gatinha pega um sol no clube. (KZUKA, 2010a, ed. 145, p.5).

Ao soltar algumas "amarras" na escrita do texto, o Caderno Kzuka emite juízos de valor a respeito de algo ou alguém, indicando o que é bom ou mau, certo ou errado, aceito ou repudiado, desejado ou não.

Mas o Kzuka não recorre apenas à gíria como forma de produzir uma interação informal com o/a leitor/a. Outros recursos, tais como o uso de um termo gerado pelo "encurtamento" de outro termo, o uso de um sinal gráfico para substituir uma palavra e o estilo hiperbólico de exagero, são utilizados. Exemplos disso podem ser observados nos excertos abaixo, em que aparece, respectivamente, referência à palavra apartamento por meio do termo "apê", substituição de "adicionado a" ou "junto a" pelo sinal gráfico +, além de palavras grafadas com repetições de letras para indicar que os integrantes da Banda Metálica teriam pedido que quantidades exageradas de alguns artigos fossem disponibilizadas no camarim do show que fizeram em Porto Alegre.

$O$ notebook e o modem $3 G$ tinham lugar garantido entre as roupas, pares de sapatos $e$ maquiagens nas oito malas que se espalham pelo apê. (KZUKA, 2010b, ed. 146, p.5).

A combinação blusa larga + shortinho é uma boa pedida para a noite da virada, por ser confortável e lindo. (KZUKA, 2009b, ed. 140, p.4).

Entre refrigerantes, energético e тиииииita água, os caras pediram leite desnatado e leite de soja sem açúcar. (KZUKA, 2010a, ed. 145, p. 04).

Outro ponto a destacar na discussão que estamos conduzindo neste texto a respeito do periódico Kzuka é a ruptura que se faz nesse mesmo caderno de jornal com o uso recorrente da terceira pessoa no texto jornalístico como forma tentar creditar confiabilidade ao mesmo. O uso da terceira pessoa, o narrador onisciente, como diz Benites (2002), produziria uma sensação de que a notícia se põe como verdadeira, ou seja, cria-se um efeito de realidade. Um efeito que tem sido reforçado pela veiculação de dados coletados no local onde algo ocorreu, como, por exemplo, nome das pessoas envolvidas, data, hora e localização.

\footnotetext{
${ }^{5}$ Referindo-se a camisetas.
} 
BICCA, A. D. N.; CUNHA, A. P. A.; BIERHALS, R. N.

No entanto, essa estratégia não tem sido usada quando o objetivo de um jornal é buscar cativar seus/suas leitores/as. Ao buscarem "falar" diretamente com quem está lendo a matéria, muitos textos jornalísticos têm incorporado o uso da primeira e da segunda pessoas. A estratégia de redigir o texto em primeira pessoa, por exemplo, tem sido usada com muita frequência quando o objetivo é conquistar leitores/as jovens que não querem ler um jornal sem emoção, sem cor e sem vida, como comentou Noblat (2003).

Porém, no jornal Kzuka, encontramos o uso da segunda pessoa. Os excertos abaixo se valem desse recurso, não apenas para criar intimidade com seus/suas leitores/as, mas também para evocar o hábito dos gaúchos de usarem predominantemente o tu ao invés do você, como é bem mais frequente em outras regiões do país.

Te liga! A galera do Kzuka estará fazendo cobertura na praia durantes (sic) os finais de semana de verão. (KZUKA, 2010a, ed. 145, p.08).

E tuas aulas, acabam quando? Para que série tu passou? (KZUKA, 2009b, ed.140, p.8).

O que tu estavas fazendo no momento da foto? (KZUKA, 2009b, ed. 140, p.8).

Em outros excertos podemos observar que, além do uso de gírias, de formas coloquiais de expressão e do direcionamento mais pessoal gerado pelo uso da segunda pessoa, usam-se perguntas feitas ao/à leitor/a como se ele/ela pudesse responder imediatamente à questão. Ou, ainda, aparecem no texto do jornal indicações do que o/a leitor/a deve fazer, como se não existisse um espaço de tempo entre a escrita do texto e o momento da sua leitura.

Verão é sinônimo de mar, areia e diversão, certo? Não para os "pobres coitados" que viram todos seus amigos partirem pro litoral e sobraram na cidade. (KZUKA, 2010a, ed. 145, p. 5).

Te joga no nosso site e bora agilizar essa festinha!. (KZUKA, 2010b, ed. 146, p.7).

A produção de um texto jornalístico que recorre a formas coloquiais de expressão, bem como à ruptura do uso dominante da terceira pessoa, exige que reflitamos a respeito da distinção entre língua escrita e língua falada. Em primeiro lugar, é importante destacar que a escrita tem sido considerada como um modo de registrar uma língua por meio de sinais visíveis, não se constituindo em uma pura e simples transcrição do que é falado em uma determinada língua. De acordo com Urbano (2006), a escrita é diferente da fala em gênese, organização e planejamento. A fala utiliza sons e costuma ser complementada pela entonação 
da voz e pelos gestos feitos pela pessoa que está falando. A escrita, por sua vez, utiliza letras e é complementada particularmente pela pontuação. Porém, de acordo com o autor (idem), as condições de produção de um determinado texto estão implicadas na presença de traços de maior ou menor formalidade e permitem que se conteste a existência de uma marca distintiva rígida entre o que é falado e o que é escrito. Assim, elementos que se pode considerar mais aproximados da linguagem falada podem aparecer em textos escritos e funcionar como uma das estratégias de endereçamento do texto ao público jovem.

\title{
5 CONSIDERAÇÕES FINAIS
}

Haja vista o fato de a mídia, como meio de expressão e comunicação, apresentar modelos de papéis, concepções e comportamentos, provendo informações de cunho social, cultural, político, essa pode ser considerada uma importante forma de pedagogia.

O Caderno Kzuka, publicado semanalmente no Jornal Zero Hora, tem se valido de mesclas de oralidade e escrita como forma de incorporar em suas páginas os modos como "guris" e "gurias" estabelecem interação, constituindo-se como um grupo cultural juvenil. Dessa forma, o jornal conseguiria estabelecer uma comunicação de "igual para igual" com esses/as jovens, assumindo para si modos de pertencimento, ao que é referido no próprio jornal como "a galera", ou seja, um grupo cultural formado pelos/as leitores desse veículo de comunicação. Essa suposta liberdade no uso mais coloquial de palavras e expressões dá ao Caderno um fôlego para seguir as tendências e tentar atrair e cativar o público jovem, frente a um mundo no qual televisão e internet conquistam a sua atenção. Para seduzir novos leitores, o jornal impresso adapta-se, liberta-se das regras e padronizações tradicionais. Enfim, usa efeitos de oralidade no sentido de criar cumplicidade, especialmente, nesse contexto, com a "galera" jovem.

\section{ORALITY MARKS IN CADERNO KZUKA - A LOOK UNDER THE PERSPECTIVE OF CULTURAL STUDIES}

\author{
Abstract


BICCA, A. D. N.; CUNHA, A. P. A.; BIERHALS, R. N.

Through this study we seek to understand how orality markers present in journalism are implicated in the constitution of youth cultural identities. Under the perspective of the Cultural Studies, we discuss, throughout the discursive approach of Cultural Representation, the ways how the Caderno Kzuka - a weekly periodic published in the South-Brazilian newspaper called "Zero Hora" - promotes a sort of Cultural Pedagogy, by incorporating typically juvenile expressions and elements into the text written in the newspaper.

Keywords: Journalism; Orality; Cultural Pedagogies; Identities

\section{MARCAS DE ORALIDAD EN EL CADERNO KZUKA - UN ENFOQUE DESDE LA PERSPECTIVA DE LOS ESTUDIOS CULTURALES}

\section{Resumen}

En este estudio, hemos tratado de entender cómo las marcas de oralidad presentes en el periodismo están involucradas en la formación de las identidades culturales juveniles. Sobre la base de los Estudios Culturales, argumentamos, a partir del enfoque discursivo de representación cultural, las formas en que el Caderno Kzuka - boletín semanal del diario gaucho "Zero Hora" - promueve una forma de educación cultural, incorporando expresiones y elementos típicamente juveniles al texto escrito en el semanario.

Palabras clave: Periodismo; Oralidad; Pedagogías Culturales; Identidades

\section{REFERÊNCIAS}

ANDER-EGG, Ezequiel. Periodismo Popular. Buenos Aires: Instituto de Ciências Sociales Aplicadas, 1993.

BAUMAN, Zigmunt. Identidade. Rio de Janeiro: Jorge Zahar Editor, 2005.

BENITES, Sonia Aparecida Lopes. Contando e Fazendo História: a Citação no Discurso Jornalístico. São Paulo: Arte \& Ciência, Assis: Núcleo Editorial Proleitura, 2002.

BERTINETTI, Camila Pozza. "FEITO DE JOVENS PARA JOVENS”: o consumo dos veículos Kzuka por jovens de Ensino Médio de Porto Alegre - RS. 2009. 85f. Trabalho de Conclusão do Curso (Graduação em Comunicação Social) - Universidade Federal do Rio Grande do Sul, Porto Alegre. 
BORDENAVE, Juan Díaz. O Que é Comunicação. $8^{\text {a }}$ Ed. São Paulo: Editora Brasiliense, 1986.

CANEVACCI, Massimo. Culturas eXtremas. Mutações juvenis nos corpos das metrópoles. Rio de Janeiro: DP \& A, 2005.

CUNHA, A. P. A.; BIERHALS, R. N. Fique ligado no que vai rolar nas próximas páginas! Efeitos de oralidade no jornalismo impresso. Calidoscópio, São Leopoldo: Universidade do Vale do Rio dos Sinos, v. 12, n. 2, p. 180-190, mai/ago 2014.

DIAS, Ana Rosa Ferreira. O Discurso da Violência: As Marcas da Oralidade no Jornalismo Popular. São Paulo: EDUC/Cortez, 1996.

ELLSWORTH, Elizabeth. Modos de Endereçamento: uma coisa de cinema; uma coisa de educação também. In: SILVA, Tomaz Tadeu da. (org.). Nunca fomos humanos: nos rastros do sujeito. Belo Horizonte: Autêntica, 2001.

GIROUX, Henry. Memória e Pedagogia no Maravilhoso Mundo da Disney. In: SILVA, Tomaz Tadeu da. (org.). Alienígenas na sala de aula: uma introdução aos Estudos Culturais em Educação. Petrópolis: Vozes, 1995.

HALL, Stuart. Representations and signing produces. London: Sage, Open University, 1997. Quem precisa da identidade? In: SILVA. Tomaz Tadeu da. (org.) Identidade e diferença: A perspectiva dos Estudos Culturais. Petrópolis: Vozes, 2005.

KELLNER, Douglas. A Cultura da Mídia. Estudos Culturais: identidade e política entre o moderno e o pós-moderno. Baurú: EDUSC, 2001.

LAGE, Nilson. Linguagem Jornalística. 6a Ed. São Paulo: Editora Ática, 1998.

KZUKA. Porto Alegre: Jornal Zero Hora, Ed. 139, dezembro de 2009.

KZUKA. Porto Alegre: Jornal Zero Hora, Ed. 140, dezembro de 2009.

KZUKA. Porto Alegre: Jornal Zero Hora, Ed. 145, janeiro de 2010.

KZUKA. Porto Alegre: Jornal Zero Hora, Ed. 146, janeiro de 2010.

LAGE, Nilson. Estrutura da Notícia. 5ª Ed. São Paulo: Editora Ática, 1999.

LUSTOSA, Elcias. O Texto da Notícia. Brasília: Editora UnB, 1996.

MACHADO, Mônica. Consumo e politização: discursos publicitários e novos engajamentos juvenis. Rio de Janeiro: Mauad X: FAPERJ, 2011.

MAFFESOLI, Michel. O Tempo das Tribos. Rio de Janeiro: Forense Universitária, 2010. 
MANUAL DA REDAÇÃO: Folha de São Paulo. 5a Ed. São Paulo: Publifolha, 2002.

MARQUES, Cíntia Bueno. Pedagogia do Kzuka: um estudo sobre a produção de identidades jovens na mídia. Canoas: ULBRA. 2007. 142f. Dissertação (Mestrado em Educação) Universidade Luterana do Brasil, Canoas.

NOBLAT, Ricardo. A Arte de Fazer um Jornal Diário. 4ª Ed. São Paulo: Contexto, 2003.

ORENGO, Fernanda. Caso de ensino: Comunicação 360 - o caso Kzuka. 2009. 33f.

Monografia (Especialização em Administração) - Universidade Federal do Rio Grande do Sul, Porto Alegre.

PINTO, Milton José. Comunicação \& Discurso. $2^{\mathrm{a}}$ Ed. São Paulo: Hacker Editores, 2002.

PRETI, Dino. Variedade Lexical em Discursos Marginais: A Gíria de Grupo. In: PRETI, Dino (org.). Oralidade em Diferentes Discursos. São Paulo: Associação Editorial Humanitas, 2006.

Dicionários de Gíria. Alfa, São Paulo, 2003.

PROVIN, Priscila; FABRIS, Elí. Uso de sites na pesquisa em Educação: desafios contemporâneos para a investigação. In: $4^{\circ}$ SEMINÁRIO BRASILEIRO DE ESTUDOS CULTURAIS E $1^{\mathrm{O}}$ EDUCAÇÃ O E SEMINÁRIO INTERNACIONAL DE ESTUDOS CULTURAIS E EDUCAÇÃO, 2011, Canoas. Anais do $4^{\circ}$ SBECE e $1^{\circ}$ SIECE. Canoas: ULBRA, 23 -25, mai. 2011. p. $1-15$.

RIPOLL, Daniela. “Aprender sobre sua herança já é um começo” ou de como tornar-se geneticamente responsável... 2005, 310f. Tese (Doutorado em Educação) - Universidade Federal do Rio Grande do Sul, Porto Alegre.

RODRIGUES, Adriano Duarte. As Técnicas da Comunicação e da Informação. Lisboa: Editorial Presença, 1999.

RODRIGUES, Jacira Werle. Reportagem Impressa, Estilo e Manuais de Redação: a Construção da Autoria nos Textos do Jornalismo Diário. Santa Maria: FACOS/UFSM, 2003.

SCHMIDT, Saraí. Ter atitude: escolhas da juventude líquida. Um estudo sobre mídia, educação e cultura jovem global. 2006, 201f. Tese (Doutorado em Educação). - Universidade Federal do Rio Grande do Sul, Porto Alegre.

SILVA, Tomaz Tadeu. A produção social da identidade e da diferença. In: SILVA. Tomaz Tadeu da. (org.) Identidade e diferença: A perspectiva dos Estudos Culturais. Petrópolis: Vozes, 2005.

STEINBERG, Sirley. Kindercultura: a construção da infância pelas grandes corporações. In: SILVA, Luiz Heron da; AZEVEDO, José Clovis de; SANTOS, Edmilson Santos dos. (Orgs.). Identidade social e a construção do conhecimento. Porto Alegre: SMED, 1997.

URBANO, Hudinilson. Usos da Linguagem Verbal. In: PRETI, Dino (org.). Oralidade em 
Diferentes Discursos. São Paulo: Associação Editorial Humanitas, 2006. p. 19-55.

VELHO, Gilberto. Juventudes, projetos e trajetórias na sociedade contemporânea. In:

ALMEIDA, Maria Isabel Mendes de e EUGENIO, Fernanda (orgs.). Culturas Jovens: Novos Mapas do Afeto. Rio de Janeiro: Jorge Zahar Editor, 2006. p 192-200.

VILAS BOAS, Sérgio. O Estilo Magazine: o Texto em Revista. São Paulo: Summus, 1996.

WOODWARD, Kathryn. Identidade e diferença: uma introdução. In: SILVA. Tomaz Tadeu da. (org.) Identidade e diferença: A perspectiva dos Estudos Culturais. Petrópolis: Vozes, 2005. p. 7- 72.

\section{Referências eletrônicas}

GARBIN, Elisabete. Culturas juvenis, identidades e internet: questões atuais. Revista Brasileira de Educação, Rio de janeiro: ANPED, n. 23, maio-ago. 2003. http://dx.doi.org/10.1590/S1413-24782003000200009.

KZUKA. Site. Disponível em < www.kzuka.com.br >. Acesso em: 27 set. 2014.

MATOS, Patrícia. O nerd virou cool: identidade, consumo midiático e capital simbólico em uma cultura juvenil em ascensão. In: XVI CONGRESSO DE CIÊNCIAS DA COMUNICAÇÃO NA REGIÃO SUDESTE; 2011, São Paulo. Anais do XVI Congresso de Ciências da Comunicação na Região Sudeste. São Paulo: Intercom, 12 -14, mai. 2011, p. 115.. Disponível em: < http://www.intercom.org.br/papers/regionais/sudeste2011/resumos/R24-1149-1.pdf $>$ Acesso em: 03 ago. 2011.

Data de recebimento: 30/09/2015

Data de aceite: 12/01/2016 